\title{
Educating the Out-of-school Youth on Entrepreneurship: Community Extension Program Impact Study
}

\author{
Rachel A. Baladjay * \\ Mauro Allan P. Amparado ** \\ Jocelyn Manatad * \\ Micaela Rosal *
}

\section{mapamparado@gmail.com \\ University of Cebu Lapu-Lapu and Mandaue, Mandaue City, Cebu, Philippines}

* Faculty, College of Business \& Accountancy, UCLM

** Director, Community Awareness, Relations \& Extension Services

\section{Abstract}

This descriptive qualitative study explored the efforts of the College of Business and Accountancy faculty and nonteaching staff of the university as they educate 15 Out-ofschool young adults on entrepreneurship. Narratives revealed the experiences of the beneficiaries in the community extension program and its impact to the informants.

One-on-one interviews were conducted to 15 Out-ofschool youth of the Life Project for Youth. The interviews were conducted for 4 consecutive Saturdays with one hour of interview per young adult.

Findings revealed two common themes: I have learned new lessons; and I will be an entrepreneur in the future. With interviews conducted in one month, the researchers recommend the continuation of the program to fully equip the 
out-of-school youth on this endeavor. It is also recommended by the researchers that students should take part in the dissemination of information and knowledge to LP4Y beneficiaries. A follow up study is highly recommended after 2 years of teaching the beneficiaries under the entrepreneurship program.

Keywords: Life Project for Youth, Philippines, Entrepreneurship Program, New lessons learned, Out-ofschool Youth, Impact study

\section{Introduction}

Poverty is experienced when people are unemployed because they do not have the money to buy things that they need. To avoid poverty and lead better, and possibly have a more fulfilling life, youth development and empowerment are vital stages in life for building the human capital. The human capital formed in youth is thus an important determinant of long-term growth that a nation can invest on. Hence, making sure that youths are well prepared for their future is enormously important to the course of poverty reduction and growth (Arogundade, 2011).

The creation and proliferation of young and dynamic, small enterprises have been positively identified as an important strategy for creating new jobs, and hastening the economic recovery and growth of the country. Thus, various sectors of society, including government, private business, civic associations, non-governmental organizations, and even church groups, have allocated a substantial part of their resources for entrepreneurship development and promotion of small-scale enterprises (Awogbenle \& Iwuamadi, 2010). 
Youth development empowerment are vital stages in life for building the human capital that allows young people to avoid poverty and lead better, and possibly have a more fulfilling life. The human capital formed in youth thus an important determinant of long-term growth that a nation can invest on. Hence, making sure that youths are well prepared for their future is enormously important to the course of poverty reduction and growth (Rasheed \& Rasheed, 2003).

Within the frameworks of potential efforts and strategies to boost employment and job creation for young people, entrepreneurship is increasingly accepted as an important means and a valuable additional strategy to create jobs and improve livelihoods and economic independence of young people. Regrettably, problems of unemployment as experience by the educated youths and even the uneducated but skilled youths have become more pathetic in many developing economies, despite the neo-liberal strategies in addressing the issue of enhancing human capital (Awogbenle \& Iwuamadi, 2010).

Identifying and nurturing entrepreneurial potential among youth can have long-term implications for Philippine economic development. Prior research suggests that identifying and nurturing potential entrepreneurs throughout the education process could produce many long-term economic benefits. Specifically, a venture support system based on entrepreneurship education designed to stimulate and facilitate entrepreneurial activities, could result in a lower unemployment rate, increased establishment of new companies, and fewer failures of existing businesses.

Entrepreneurship education can also be an important component of economic strategies for fostering job creation. More specifically, effective youth entrepreneurship education 
prepares young people to be responsible, enterprising individuals who become entrepreneurs or entrepreneurial thinkers and contribute to economic development and sustainable communities (Consortium for Entrepreneurship Education). Entrepreneurship education generally refers to programs that promote entrepreneurship awareness for career purposes and provide skill training for business creation and development. It is distinguishable from other forms of business education when its purpose is creating a new product or service that results in higher economic value. An inherent assumption in entrepreneurial education is that entrepreneurship characteristics and skills can be developed. Research suggests that the propensity towards entrepreneurship has been associated with several personal characteristics that can be influenced by a formal program of education. Education can prepare for new venture initiation by transferring knowledge and developing relevant skills that improve the self-efficacy and effectiveness of the potential entrepreneur. However, a consensus on when educational intervention is most effective in developing entrepreneurial potential has not been clearly established.

An entrepreneur is an innovating individual who has developed an ongoing business activity where none existed before. Meredith in 1983 as quoted by Arogundade made the following observation about who an entrepreneur is: an entrepreneur as a person or persons who possess the ability to recognize and evaluate business opportunities, assemble the necessary resources to take advantage of them and take appropriate action to ensure success. Entrepreneurs are people who constantly discover new markets and try to figure out how to supply those markets efficiently and make a profit. He [she] is a person that searches for change, responds to change, and exploits change by converting change into business opportunity (Arogundade, 2011). 
Many developed countries became developed mainly because of the concerted efforts of the small business proprietors called entrepreneurs. Taken together, their efforts gave rise to countries like the United States of America, The United Kingdom and many countries in Europe. Their economies grew because of the contribution of the entrepreneurs in employment, income, government taxes and availability of goods and services.

At the heart of Life Project for Youth lies a deep-seated concern with the catastrophic situation facing a growing number of excluded youth worldwide. It turns out that these excluded young adults, who have managed to survive life in the streets have done so by developing some of the same skills as entrepreneurs. This became apparent to Life Project for Youth founders over the course of one year spent visiting major cities in 23 different countries. And all these young individuals need a place where they can learn to channel those skills, allowing them to become active members of a decent world (en.lp4y.org).

A group of friends, entrepreneurs and young people, in Europe and the USA, came together to create Life Project for Youth, an organization which is $100 \%$ dedicated to the integration of young excluded victims of extreme poverty. They decided to create Life Project Centers, incubators for entrepreneurial projects, close to the heart of slum areas, where excluded young adults receive all necessary support as they make their way towards social and professional inclusion (en.lp4y.org).

Life Project Centers provide an ideal environment where young adults can develop their life projects and work towards social and financial autonomy, allowing them 
eventually to become agents for development in their communities. Each center houses 1 to 3 programs, each consisting of 15 young adults who benefit from a specially designed pedagogy known as Professional Training for Entrepreneurs (en.lp4y.org).

One of the institutional goals of the University of Cebu Lapu-Lapu and Mandaue is to develop social awareness, responsibility and accountability among stakeholders anchored on instruction, research and production (Amparado, 2013). UCLM through its community extension arm, Community Awareness, Relations \& Extension Services entered into a memorandum of agreement with LP4Y. With the assistance of the College of Business and Accountancy and the non-teaching departments, several training and seminar-workshops were conducted to the outof-school youth of the Life Project for Youth (LP4Y) from 2015 to 2017. This aims to develop their entrepreneurial skills and ability to manage micro, small and medium enterprises (MSME).

Hence, this qualitative study explores the efforts of the College of Business and Accountancy faculty and nonteaching staff of the university as they educate 15 Out-ofschool young adults on entrepreneurship. Narratives revealed the experiences of the beneficiaries in the community extension program and its impact to the informants.

\section{Methods}

This study utilized the descriptive qualitative design. One-on-one interviews were conducted to 15 Out-of-school youth of the Life Project for Youth. The interviews were 
conducted for four consecutive Saturdays with one hour of interview per young adult.

Narratives were taken from each Life Project for Youth beneficiary and was used to analyze the findings of the interview. In the first step, the researchers describe each person participating in the study to gain a sense of the participants. Next, the researchers extract statements with significance to the research question. To analyze the significant statements, the researchers articulated what the statements mean and creates themes from the meanings. The researcher grouped similar themes together and organized them into categories. Finally, the researchers integrate the results into a comprehensive description of the topic and returned to each participant to verify the results. 


\section{Results and Discussion}

The following themes were revealed during the study.

\section{"I have learned new lessons"}

Lessons learned from the program according to the informants included management functions such as planning, organizing, leading and controlling. They also appreciated the value of budgeting and saving most especially that they have discovered that the money that they saved can be used as start-up capital of their planned business. Most of them are part-time workers. Some have devoted their time helping the Life Project for Youth on candle making while others have part-time jobs outside of the center. They appreciated lessons on customer service. Additional knowledge that they learned were the preparation of financial statement, recording business transactions, computation of profit, cash management and green management.

There are many business opportunities for an individual with a creative mind. This was emphasized by the lecturers in the entrepreneurship program. If they decide to put up a small or large business, it is important to follow the process of identifying and evaluating profitable business endeavors. For an entrepreneur to succeed, he must have the management skills to manage his business with knowledge on planning, organizing, leading and controlling. He should possess the appropriate skills in the business that he would like to venture on. The informants verbalized that the series of lectures prepared them to start their business.

In one study, it examined the effect of participation in an enterprise education program on perceptions of the desirability and feasibility of starting a business. Changes in 
the perceptions of a sample of secondary school students enrolled in the Young Achievement Australia enterprise program are analyzed using a pre-test post-test control group research design. After completing the enterprise program, participants reported significantly higher perceptions of both desirability and feasibility. The degree of change in perceptions is related to the positiveness of prior experience and to the positiveness of the experience in the enterprise education program. Self-efficacy theory is used to explain the impact of the program. Overall, the study provides empirical evidence to support including exposure to entrepreneurship education as an additional exposure variable in entrepreneurial intentions models (Petterman \& Kennedy, 2003).

\section{"I will be an enterpreneur in the future"}

An entrepreneur is creative and innovative. He is a person who starts something new in the market. $\mathrm{He}$ is an owner-manager and willing to take risks. Usually he is someone not willing to work for others. Instead he wants others to work for him. They may be engaged in either small or medium business. Entrepreneurs are willing to do whatever it takes to succeed, if not now, maybe in some future time, but they keep on pursuing their desire to succeed. They have no one to answer to. They are their own bosses. The entrepreneur has a way of controlling the outcome. The outcome is not left to chance. Becoming an entrepreneur is not just another alternative career path. Rather, entrepreneurship can be every bit as prestigious, as challenging, and in many instances, more financially rewarding as the practice of law, medicine, education, the arts, and other conventional professions. The informants verbalized that one day, their dreams of becoming an entrepreneur will be realized. 
In another study, the researchers examined the characteristics and role of the entrepreneur and the challenges for business schools posed by the need to develop more enterprising individuals. It argues that the traditional education system stultifies rather than develops the requisite attributes and skills to produce entrepreneurs, and proposes that if entrepreneurs are to be developed, considerable changes are required in both the content and process of learning. In particular it suggests that there needs to be a shift in the emphasis from educating "about" entrepreneurship to educating "for" it. Stresses equally that entrepreneurship should not be equated with new venture creation or small business management, but with creativity and change. In this context, the paper proposes that educational institutions need to change the process of learning to enable their students to develop their right brain entrepreneurial capabilities as well as their left-brain analytical skills. As Chia argues, business schools need to weaken the thought processes so as to encourage and stimulate the entrepreneurial imagination (Kirby, 2004).

In another article, it explored different themes within entrepreneurship education via the use of a systematic literature review (SLR). Systematic literature reviews are recognized methods for conducting evidence-based policy. The particular approach to the SLR used in this study is explained and the article explores the findings outlining a thematic framework drawn from narrative coding. The findings support the conclusion that entrepreneurship education has had an impact on student propensity and intentionality. What is unclear is the extent to which such education impacts on the level of graduate entrepreneurship or whether it enables graduates to become more effective entrepreneurs. The findings also highlight a lack of 
consensus on what entrepreneurship or enterprise education actually 'is' when implemented in practice (Pittaway \& Cope, 2007).

\section{Conclusion and Recommendations}

In line with the vision-mission statement of the university "to give hope and transform lives," the entrepreneurship program is a promising avenue for faculty members to impart knowledge on business and management. This has opened the minds of the beneficiaries of the entrepreneurship program to new possibilities in their lives.

The Life Project for Youth has provided skills training on the candle project. The entrepreneurship program of the university is a timely and relevant opportunity for the beneficiaries to manage their products and to improve the operations of the center's business. Within a span of one year, the university has provided various concepts to them. The researchers recommend the continuation of the program to fully equip the out-of-school youth on this endeavor. It is also recommended by the researchers that students should take part in the dissemination of information and knowledge to LP4Y beneficiaries. A follow up study is highly recommended after 2 years of teaching the beneficiaries under the entrepreneurship program.

\section{Literature Cited}

Amparado, M. A. P. (2013). University of Cebu Research Center Manual. Philippines: University of Cebu.

Arogundade, B. B. (2011). Entrepreneurship education: An 
imperative for sustainable development in Nigeria. Journal of emerging trends in educational research and policy studies (JETERAPS), 2(1), 26-29.

Awogbenle, A. C., \& Iwuamadi, K. C. (2010). Youth unemployment: Entrepreneurship development programme as an intervention mechanism. African Journal of Business Management, 4(6), 831.

Kirby, D. A. (2004). Entrepreneurship education: can business schools meet the challenge?. Education+ training, 46(8/9), 510-519.

Peterman, N. E., \& Kennedy, J. (2003). Enterprise education: Influencing students' perceptions of entrepreneurship. Entrepreneurship theory and practice, 28(2), 129-144.

Pittaway, L., \& Cope, J. (2007). Entrepreneurship education: a systematic review of the evidence. International small business journal, 25(5), 479-510.

Rasheed, H. S., \& Rasheed, B. Y. (2003). Developing entrepreneurial characteristics in minority youth: The effects of education and enterprise experience. In Ethnic entrepreneurship: Structure and process (pp. 261-277). Emerald Group Publishing Limited.

en.lp4y.org 